Şeref, i. ve Çinpolat, E. (2021). Türkçe öğretmenlerinin öğretim yöntem ve tekniklerini kullanma becerileri ile öğretmen öz yeterlikleri arasındaki ilişki. Ana Dili Eğitimi Dergisi, 9(4), 1051-1065.

Ana Dili Eğitimi Dergisi
Journal of Mother Tongue Education
www.anadiliegitimi.com
Geliş/Received: 01.04 .2021 Kabul/Accepted: 12.10 .2021
Araştırma Makalesi / Research Paper

\title{
Türkçe Öğretmenlerinin Öğretim Yöntem ve Tekniklerini Kullanma Becerileri ile Öğretmen Öz Yeterlikleri Arasındaki ilişki
}

\author{
izzet ŞEREF* \\ Enes ÇINPOLAT ${ }^{* *}$
}

\begin{abstract}
Öz
Bu araştırmanın amacı Türkçe öğretmenlerinin yöntem ve teknik kullanma becerileri ile öğretmen öz yeterlik inançları arasındaki ilişkiyi incelemektir. Araştırma, bağımsız bir değişkenin manipülasyonunun olmadığı nicel araştırma desenlerinden ilişkisel araştırma modeli ile gerçekleştirilmiştir. Kartopu örnekleme yöntemi ile Türkiye'nin farklı illerindeki eğitim kurumlarında görev yapan 145 Türkçe öğretmeni çalışmaya katılmıştır. Araştırmada verilerin toplanması amacıyla "Türkçe Öğretim Yöntem ve Tekniklerini Kullanma Becerisi Ölçeği", "Öğretmen Özyeterlik Inancı Ölçeği” ve araştırmacılar tarafından hazırlanan kişisel bilgi formundan yararlanılmıştır. Veriler, SPSS ve JASP bilgisayar programları kullanılarak bağımsız gruplar t-testi, tek yönlü ANOVA, Pearson momentler çarpımı korelasyon katsayısı ve basit doğrusal regresyon analizi kullanılarak çözümlenmiştir. Araştırmadan elde edilen bulgulara göre Türkçe öğretmenlerinin yöntem-teknik kullanma becerileri ile öğretmen öz yeterlikleri arasında pozitif yönlü anlamlı ilişki olduğu ve öğretmenlerin yöntem-teknik kullanma becerilerinin öğretmen öz yeterliği toplam varyansının \%34'ünü açıkladığı sonuçlarına ulaşılmıştır.
\end{abstract}

Anahtar Kelimeler: Türkçe öğretmeni, yöntem-teknik, öğretmen öz yeterliği, ilişki.

\section{The Relationship between Turkish Teachers' Use of Instructional Methods and Techniques Skills and Teacher Self-Efficacy}

\begin{abstract}
The aim of this study is to examine the relationship between Turkish teachers' method and technique usage skills and teachers' self-efficacy beliefs. It was carried out using the correlational research model, which is one of the non-experimental quantitative research methods in which there is no manipulation of an independent variable. 145 Turkish teachers working in various cities in Turkey were chosen to participate in the study using the snowball sampling method. In order to collect data for the study, the personal information forms created by the researchers, "The Ability to use the Turkish Teaching Methods and Techniques Scale", and "Teacher Self-Efficacy Scale", were used. In the analysis of the data, independent groups t-test, one-way ANOVA, Pearson product-moment correlation coefficient, and simple linear regression analysis were used via the software: SPSS and JASP. According to the findings of the research there is a positive and significant relationship between the method-technique usage skills and teacher self-efficacy of Turkish teachers and the teachers' method-technique usage skills explain $34 \%$ of the total variance of teacher self-efficacy.
\end{abstract}

Keywords: Turkish language teacher, method-technique, teacher self-efficacy, relationship.

\footnotetext{
* Doç. Dr., Sivas Cumhuriyet Üniversitesi, Eğitim Fakültesi, Türkçe ve Sosyal Bilimler Eğitimi Bölümü, Sivas, izzetseref@cumhuriyet.edu.tr, ORCID: 0000-0002-2379-1373

${ }^{* *}$ Arş. Gör., Ordu Üniversitesi, Eğitim Fakültesi, Türkçe ve Sosyal Bilimler Eğitimi Bölümü, Ordu, enescinpolat@gmail.com, ORCID: 0000-0002-3411-4300
} 


\section{Giriş}

Kişinin olası durumları yönetmek için gerekli eylem planlarını organize etme ve yürütme yeteneklerine olan inançlarını ifade eden öz yeterlik kavramı (Bandura, 1997), Bandura (1977) tarafından sosyal bilişsel kuram içerisinde ele alınmıştır. Yeterlik inancı insanların nasıl düşündüğünü, hissettiğini, kendilerini nasıl motive ettiğini ve nasıl davrandığını etkiler (Bandura, 1997, s. 2). Öz yeterlik kavramına bakıldığında, bunun çok daha geniş bir içeriği karşıladığı görülmektedir. Çünkü öz yeterlik insanın karşılaşabileceği tüm olaylara karşı duruşunu ele almaktadır. Yani bu kavram özel olarak öğretmenlik mesleği ile ilgili değildir. Bu da özel olarak öğretmenlik mesleğine ilişkin öz yeterliğin incelenmesine dair bir çalışma alanı oluşmasına imkân sağlamıştır. 1970'li yıllarda öğretmen yeterliği ile ilgili yürütülen çalışmalarda Bandura'nın kuramına değinilmemiş (Dellinger, Bobbett, Oliver ve Ellett, 2008); 1980'li yıllardan sonra öğretmen öz yeterliği ile ilgili çalışmalar hız kazanmıştır (Çapa-Aydın, Uzuntiryaki-Kondakçı, Temli ve Tarkın, 2013). Böylelikle öğretmen öz yeterliği konusuna olan ilgilin kuramsal temelli çalışmaların yapılması ile başladığı ve günümüze gelindikçe bu ilginin arttığı söylenebilir.

Yukarıda belirtildiği gibi öğretmen yeterlikleri ile ilgili çalışmalar hız kazandıkça bu alandaki kavramsal tanımlar da artmaya başlamıştır. Ashton (1985, s. 142) öğretmen yeterliğini, "öğretmenlerin öğrencilerin öğrenmesi üzerinde olumlu bir etkiye sahip olma yeteneklerine olan inancı"; Guskey ve Passaro (1994, s. 4) "öğretmenlerin, zor veya motivasyonu olmayan öğrenciler için bile onların ne kadar iyi öğrendiklerini etkileyebileceklerine dair inancı veya kanısı"; Tschannen-Moran, Hoy ve Hoy (1998, s. 233) da "öğretmenin belirli bir bağlamda belirli bir öğretim görevini başarılı bir şekilde gerçekleştirmek için gereken eylemleri organize etme ve yürütme kabiliyetine olan inancı" olarak aktarmaktadır. Öğretmen öz yeterliği ise "öğretmenin, belirli bir durumda belirli bir kalite düzeyinde belirli öğretim görevlerini yerine getirme yeteneklerine olan bireysel inançları" olarak tanımlanmaktadır (Dellinger, Bobbett, Oliver ve Ellett, 2008, s. 752). Öğretmen yeterliği, öğretmen davranışı, çaba düzeyi, coşku, planlama, kararlılık, yaratıcılık, daha zor öğrencilerle çalışma isteği ve öğretime bağlılık ile ilgili bir kavramdır (Tschannen-Moran, Hoy ve Hoy, 1998). Dellinger (2001) öğretmen yeterliği ve öğretmen öz yeterlik inançlarının farklı yapılar olduğu teorisini öne sürerek bu iki kavramın farklı şekilde kavramsallaştırılması ve ölçülmesi gerektiğini belirtmektedir. Bu şekilde çeşitli kavramsal ayrımlar bulunsa da tanımlardan da görüleceği gibi bu kavramlar öğretim faaliyetlerinin yürütülmesi ve kalitesine etki eden bir durum olarak değerlendirilebilir.

Aşağıda, öğretmen yeterliliklerinin eğitim-öğretim alanındaki etkilerine ilişkin literatürdeki çeşitli araştırma sonuçlarından hareketle bilgiler sunulmuştur. Böylelikle öğretmen öz yeterliğinin çeşitli açılardan önemi daha net görülebilir. Allinder (1994) öğretmen yeterliği yüksek olan öğretmenlerin kendilerine daha fazla güvendiklerini, daha planlı ve öğretime daha istekli olduklarını belirtmiştir. Ashton ve Webb (1986), öğretmenlerin öğretim yeterliklerine ilişkin inançlarının, öğrencilerin eğitim-öğretim yılı boyunca akademik başarı düzeylerini yordadığını bildirmiştir. Federici ve Skaalvik (2012), öğretmen öz yeterliğinin iş tatmini ile pozitif ve duygusal tükenme ile negatif ilişki içinde olduğunu tespit etmiştirler. Infurna, Riter ve Schultz (2018) da öğretmen öz yeterliğinin iş tatmini ile pozitif yönde ilişkili olduğunu belirtmektedirler. Moore ve Esselman (1992) öğretmenlerin öz yeterlik duygusu, başarı gibi olumlu öğrenci çıktıları ile ilişkili olduğunu belirtmektedirler. Pajares (1996) öğretmen yeterliğinin öğrenci başarısının anlamlı belirleyicisi olduğunu aktarmıştır. Skaalvik ve Skaalvik (2007) öz yeterliliğin öğretmenlerin öğretim stratejilerine etki ettiği bilgisine ulaşmışlardır. Soodak ve Podell (1993) öz yeterliği daha yüksek olan öğretmenlerin öğretme istekleriyle birlikte öğretmenlik konumunda kalmaya devam etme olasılıklarının da daha yüksek olduğunu bildirmişlerdir. Woolfolk ve Hoy (1990), öğretim yeterliliğine inanan öğretmenlerin öğrencilerin akademik özyönetimlerinin gelişimini desteklediğini aktarmaktadır. Bunların dışında Tschannen-Moran ve Hoy (2001) öğretmenlerin öz yeterlik düzeylerinin düşük olmasının öğrenci katılımı ve davranışları üzerinde olumsuz etkisi olabileceğini belirtmişlerdir. Araştırma sonuçları öğretmen öz yeterliğinin eğitimöğretim alanına büyük katkılarının olduğunu ortaya koymaktadır. Bu katkıların sağlanabilmesi için öğretmenlerin öz yeterlik algılarının yüksek olması bir gerekliliktir. Öz yeterlik algısını etkileyebilecek bir durum da öğretmenin yöntem-teknik kullanım becerisi olabilir. Çünkü formel eğitim sürecinde dersler öğretim programı tarafından belirtilen veya önerilen yöntem ve tekniklere göre işlenmektedir. 
Türkçe Öğretmenlerinin Öğretim Yöntem ve Tekniklerini Kullanma Becerileri ile Öğretmen Öz Yeterlikleri Arasındaki ilişki

Öğretmenin de bunlar hakkında uzmanlaşması, mesleğinin gerekliliklerini daha iyi yerine getireceğine olan inancını etkileyebilir.

Formel eğitim-öğretim sisteminde belirli bir öğretim programı üzerinden öğretim yapıldığı için yöntem ve teknik kullanımı bir mecburiyettir. Dal ve Tatar (2017) öğretim yöntemini "öğretmenin bir içeriği öğretmek öğrencinin de öğrenmek için çabalarını örgütlemeye yönelik -belirlenen strateji doğrultusunda- seçilen yol" (s. 27); öğretim tekniğini ise "amaca ulaşmak için seçilen yöntemlerin uygulanma biçimidir" (s. 28) şeklinde aktarmaktadır. Buradan hareketle öğretim yöntemi kavramı, hedefe yönelik dersin işleniş mantığı (yolu) olarak tanımlanabilir. Öğretim tekniği ise bu mantığa uygun bir şekilde yapılan sınıf içi uygulamalarıdır denilebilir. Arıcı (2006) dersi plansız, yöntemsiz işlemenin, konuyu öğrencilere kavratmanın oldukça zor olduğunu belirtmiştir. Dal ve Tatar (2017) da doğru yöntem ve teknik kullanımı sayesinde dersin amacına ulaşma düzeyinin yüksek olacağını belirtmektedir. Türkçe Dersi Öğretim Programı'nda (MEB, 2019, s. 8) "Öğrenme Öğretme Yaklaşımı” başlığında "Dil öğrenimi doğrusal bir faaliyet olmadığından dört temel dil becerisinin kazandırılmasında tek bir öğrenme öğretme yaklaşımı benimsenmemeli, farklı öğretim yöntem ve teknikleri bir arada ve dengeli şekilde kullanılmalıdır." şeklindeki uyarı ile dil öğretimi konusunda çeşitli yöntem ve tekniklerden yararlanmanın gerekliliği vurgulanmaktadır. Programda da belirtildiği gibi dil öğretiminde kişilerin özelliklerine göre yöntem ve tekniklerin çeşitlendirilmesi gerekmektedir. Buradan hareketle kullanılacak yöntem ve tekniklerin öğretmenler tarafından kavranması oldukça önemlidir.

Ulusal literatür incelendiğinde, çeşitli uygulamalarla öğretmen öz yeterliklerinin geliştirilmesinin amaçlandığı (Ekici, 2008; Kutluca ve Aydın, 2016; Yaman ve Yalçın, 2005; Yıldız, 2012); öğretmenlerin ve öğretmen adaylarının öğretmen öz yeterliklerinin incelendiği (Aslan ve Kalkan, 2018; Azar, 2010; Ekici, 2006; Korkut ve Babaoğlan, 2012; Üstüner, Demirtaş, Cömert ve Özer, 2009; Yeşilyurt, 2013); öğretmen öz yeterliği ile özerklik desteği arasındaki ilişkinin incelendiği (Güvenç, 2011); öğretmen öz yeterliği ile öğrenme yaklaşımları arasındaki ilişkinin ele alındığı (Ekinci, 2015); öğretmen öz yeterliği ile pedagojik içerik bilgisi arasındaki ilişkinin incelendiği (Akgün, 2013); öğretmen öz yeterliği ile zekâ türleri arasındaki ilişkinin incelendiği (Berkant ve Ekici, 2007); öğretmen öz yeterliği ile yaşam doyumu arasındaki ilişkinin incelendiği (Recepoğlu, 2013); öğretmen öz yeterliği ve epistemeolojik inançların arasındaki ilişkinin incelendiği (Izgar ve Dilmaç, 2008); öğretmen öz yeterliği ile mesleki tutum arasındaki ilişkinin incelendiği (Arastaman, 2013; Bakaç ve Raşit, 2017; Bayraktar, Vural-Batık ve Barut, 2016; Demirtaş, Cömert ve Özer, 2011; Nakip ve Özcan, 2016) çalışmalarla karşılaşılmaktadır. Saracoğlu, Karasakaloğlu ve Evin-Gencel (2010) de Türkçe öğretmenlerinin öz yeterlik algılarını çeşitli değişkenlere göre incelemiştir. Görüldüğü üzere öğretmen öz yeterliği Türkiye'de de önemli bir çalışma alanı hâline gelmiştir.

Eğitim-öğretim alanında yöntem-teknik kullanımı önemli bir etken durumundadır. Öğretmenlerin mesleki öz yeterlik algıları da gerçekleştirilen çalışmaların bulgularından anlaşıldığı üzere eğitim-öğretimde oldukça dikkat çekicidir. Bu iki durum arasındaki ilişkinin belirlenmesi, hâlihazırdaki literatüre farklı bir bakış açısı sunmak adına gerekli görülmüştür. Böylelikle Türkçe derslerinde öğretmenlerin yöntem ve teknik kullanma becerilerinin, öz yeterliliklerini hangi yönde ve oranda yordadığına ilişkin bir veri elde edilebilecektir.

Araştırmanın temel amacı Türkçe öğretmenlerinin yöntem ve teknik kullanma becerileri ile öğretmen öz yeterlik inançları arasındaki ilişkiyi tespit etmektir. Bunun yanı sıra aşağıdaki alt amaçlar incelenecektir:

1. Türkçe öğretmenlerinin yöntem ve teknik kullanma becerileri ile öğretmen öz yeterlik inançlarını cinsiyet değişkenine göre incelemek.

2. Türkçe öğretmenlerinin yöntem ve teknik kullanma becerileri ile öğretmen öz yeterlik inançlarını yaş gruplarına göre incelemek.

3. Türkçe öğretmenlerinin yöntem ve teknik kullanma becerileri ile öğretmen öz yeterlik inançlarını görev yılı gruplarına göre incelemek.

4. Türkçe öğretmenlerinin yöntem ve teknik kullanma becerileri ile öğretmen öz yeterlik inançlarını mezun olunan lisans programı türlerine göre incelemek.

5. Türkçe öğretmenlerinin yöntem ve teknik kullanma becerileri ile öğretmen öz yeterlik inançlarını eğitim düzeylerine göre incelemek. 


\section{Araştırmanın Modeli}

\section{Yöntem}

Araştırmacı, araştırma probleminin doğasına ve problemi ele almak için sorulacak sorulara bağlı olarak, nicel veya nitel araştırma yolunu seçer (Creswell, 2012). Bu çalışma, bağımsız bir değişkenin manipülasyonunun olmadığı nicel araştırma desenlerinden ilişkisel araştırma (Christensen, Johnson ve Turner, 2015, s. 60) ile gerçekleştirilmiştir. Creswell (2012, s. 21) ilişkisel çalışmaları araştırmacıların korelasyonel istatistiksel analizlerini kullanarak iki veya daha fazla değişken arasındaki ilişki derecesini ölçtüğü nicel araştırmadaki prosedürler olarak tanımlamaktadır. Christensen, Johnson ve Turner'a (2015, s. 61) göre "korelasyonel çalışma, iki değişkeni ölçmek ve ardından bunlar arasında var olan ilişkinin derecesini belirlemekten oluşur". Fraenkel, Wallen ve Hyun, (2012, s. 331) da "ilişkisel araştırmada, iki veya daha fazla değişken arasındaki ilişkiler, onları etkilemeye çalışmadan incelenir" şeklindeki tanımıyla değişkenlere herhangi bir etki olmadığını belirtmektedir. Bu çalışmada Türkçe öğretmenlerinin derslerde yöntem ve teknik kullanma düzeyleri ile öğretmen öz yeterlilikleri arasında nasıl bir ilişki olduğunu ortaya çıkarmak hedeflendiği için ilişkisel araştırma modeli tercih edilmiştir.

\section{Araştırma Grubu}

Araştırmanın katılımcıları kamu okullarında ve özel okullarda görev yapan Türkçe öğretmenlerinden oluşmaktadır. Katılımcılar, kartopu örnekleme tekniği kullanılarak belirlenmiştir. Kartopu örnekleme tekniğinde çalışma konusu ile ilgili birkaç referans kişi seçilir ve bu kişiler üzerinden diğer kişilere ulaşılır (Gay, Mills ve Airasian, 2011, s. 143). Referans gruptaki öğretmenlerden çalışmaya katııımları istenmiş ve ardından kendilerine gönderilen linki başka Türkçe öğretmenlerine göndermeleri sağlanmıştır. Böylelikle araştırma kapsamında Türkiye'nin çeşitli illerindeki okullarda görev yapan 145 Türkçe öğretmeni çalışmaya dâhil olmuştur. Tek bir gruptaki ilişkileri içeren deneysel olmayan tasarımlar için yaklaşık 30 gözlemin yeterli olacağı belirtilmektedir (Mertens, 2005, s. 325, akt. Robson ve McCartan, 2016, s. 144). Bu bilgiden hareketle söz konusu örneklemin yeterli görülebileceği belirtilebilir. Katılımcı öğretmenlerin, \%55,17'si kadın, \%44,82'si erkektir. \%16.55'i 21-30 yaş, \%67,58'i 31-40 yaş, \%15,86'sı 41-50 yaş aralığındadır. \%32,41'i 0-10 yıl, \%59,31'i 11-20 yıl, \%8,27'si 21-30 yıl arasında mesleki tecrübeye sahiptir. \%92,14'ü Türkçe öğretmenliği, \%7,58'i diğer lisans bölümlerinden; genel olarak ise \%77,93'ü lisans, \% 22,06'sı lisansüstü eğitim mezunudur.

\section{Veri Toplama Araçları}

\section{Türkçe Öğretim Yöntem ve Tekniklerini Kullanma Becerisi Ölçeği}

Süğümlü ve Sulak (2020) tarafından $5^{\prime}$ li likert tipinde oluşturulup geçerlik ve güvenirlik çalışması yapılan ölçek; "iş birlikli", "buluş", "sunuş" ve "araştırma inceleme yoluyla öğretim" şeklinde 4 faktör ve 26 maddeden oluşmaktadır. Bu ölçeğin Cronbach Alpha güvenirlik katsayısı .80 olarak belirlenmiştir. Ölçek geliştirme çalışmasında DFA (doğrulayıcı faktör analizi) uyum istatistikleri GFI = $.92 ; \mathrm{RMSEA}=.061 ; \mathrm{NFI}=.92 ; \mathrm{CFI}=.93 ; \chi 2 / \mathrm{df}=1.92 ; \mathrm{AGFI}=.91$ şeklinde hesaplanmıştır (Süğümlü ve Sulak, 2020). Elde edilen uyum değerlerinin ilgili literatüre göre kabul edilebilir düzeyde olduğu söylenebilir (Jöreskog ve Sörbom, 1993; Kline, 2011). Bu araştırmada ölçeğin güvenirlik analizi tekrar edilmiştir. Buna göre ölçeğin Cronbach Alpha değeri ise $.85(95 \% \mathrm{Cl}=.82, .89)$ olarak tespit edilmiştir $(n=145)$. Creswell (2012) bir ölçme aracının güvenilir olması için yeterli Cronbach Alpha kesme noktasının .70 olduğunu belirtmektedir. Bu ölçme aracı için elde edilen değer yüksek güvenirlik olarak değerlendirilebilir.

\section{Öğretmen Öz Yeterlik Inancı Ölçeği}

Çolak, Yorulmaz ve Altınkurt (2017) tarafından geliştirilip geçerlik ve güvenirlik çalışması yapılan ölçek, akademik öz yeterlik, mesleki öz yeterlik, sosyal öz yeterlik ve entelektüel öz yeterlik olmak üzere dört faktörlü, 27 maddeli ve $5^{\prime}$ li likert tipindedir. Ölçeğin doğruluğu geliştirme çalışmasında DFA (doğrulayıcı faktör analizi) ile test edilmiştir. Bu yolla ulaşılan bulgular analiz edildiğinde $\chi 2$ /sd oranının 2.12 olduğu gözlenmiştir. Diğer uyum iyiliği indekslerine ilişkin veriler ise şu şekildedir: NNFI=.97, $\mathrm{AGFI}=.82, \mathrm{GFI}=.85, \mathrm{RMSEA}=.06, \mathrm{RMR}=.03, \mathrm{CFI}=.97, \mathrm{SRMR}=.06, \mathrm{NFI}=.95$ (Çolak, 
Türkçe Öğretmenlerinin Öğretim Yöntem ve Tekniklerini Kullanma Becerileri ile Öğretmen Öz Yeterlikleri Arasındaki ilişki

Yorulmaz ve Altınkurt, 2017). Elde edilen uyum değerlerinin ilgili literatüre göre kabul edilebilir düzeyde olduğu söylenebilir (Jöreskog ve Sörbom, 1993; Kline, 2011). Ölçeğin Cronbach Alpha değeri .93 olarak tespit edilmiştir (Çolak, Yorulmaz ve Altınkurt, 2017). Bu çalışmada ölçeğin güvenirlik analizi tekrar yapılmıştır. Buna göre Cronbach Alpha değeri ise $.93(95 \% \mathrm{Cl}=.91, .94)$ olarak tespit edilmiştir (n=145). Creswell (2012) bir ölçme aracının güvenilir olması için yeterli Cronbach Alpha kesme noktasının .70 olduğunu belirtmektedir. Bu ölçme aracı için elde edilen değer yüksek güvenirlik olarak değerlendirilebilir.

Gerekli etik prosedürler takip edilerek seçilen ölçeklerin yanı sıra araştırmacılar tarafından öğretmenlere cinsiyetlerinin, yaşlarının, görev yıllarının, mezun oldukları lisans programının, eğitim düzeyinin sorulduğu kişisel bilgi formu oluşturulmuştur.

\section{Verilerin Toplanması}

Veri toplama süreci 2020-2021 eğitim-öğretim yılı güz döneminde başlamış, bahar döneminde de tamamlanmıştır. Verilerin çevrim içi yöntemle (Google Forms) toplanması uygun görülmüştür. Bu kararın verilmesinde eğitim öğretim faaliyetlerinin acil uzaktan eğitim ile gerçekleştiriliyor olması etkili olmuştur. Sonrasında 15 referans Türkçe öğretmenine ulaşılarak katılım linki iletilmiştir. Bu öğretmenlerden de tanıdıkları öğretmenlere katılım linkini göndermeleri istenmiştir. Böylelikle verilerin toplanması tamamlanmıştır.

\section{Verilerin Analizi}

Analizler, SPSS 24 ve JASP bilgisayar programları kullanılarak yapılmıştır. Bu programlar aracılığı ile yapılacak analizlerde verilerin dağılımlarının normallik değerlerine göre istatistiksel teknikler seçilmiştir. George ve Mallery'e (2003) göre dağılımın normal olduğunu varsaymak için -2 ile +2 arasındaki, Tabachnick ve Fidell'e (2007) göre ise -1.5 ile +1.5 arasındaki çarpıklık ve basıklık katsayıları yeterli kabul edilir. Çarpıklık ve basıkık katsayısı sıfıra yaklaştığında dağılımın normalliği de yükselmektedir (Tabachnick ve Fidell, 2007). Ölçme araçlarından elde edilen puanların çarpıklık ve basıklıkları - 1.5 ve +1.5 arasında değerler aldığı için verilerin normal dağılım gösterdiği söylenebilir. Bu sebeple analizde parametrik testler kullanılmıştır. Veriler, tek yönlü varyans analizi (ANOVA), Pearson momentler çarpımı korelasyon katsayısı, bağımsız gruplar t-testi, basit doğrusal regresyon analizi kullanılarak çözümlenmiştir. Anlamlılık değeri .05 olarak alınmıştır. Ayrıca korelasyson ve basit doğrusal regresyon hesaplanmasında bootstrap $(k=5000)$ uygulanmıştır.

\section{Geçerlik ve Güvenirlik}

Veri toplama araçlarına ait geçerlik ve güvenirlik bilgileri veri toplama araçları başlığı altında sunulmuştur.

\section{Araştırma ve Yayın Etiği}

Bu çalışmada "Yükseköğretim Kurumları Bilimsel Araştırma ve Yayın Etiği Yönergesi" kapsamında uyulması belirtilen tüm kurallara uyulmuştur. Yönergenin ikinci bölümü olan "Bilimsel Araştırma ve Yayın Etiğine Aykırı Eylemler" başlığı altında belirtilen eylemlerden hiçbiri gerçekleştirilmemiştir.

\section{Etik Kurul izni}

Kurul adı = Tokat Gaziosmanpaşa Üniversitesi Sosyal ve Beşerî Bilimler Araştırmaları Etik Kurulu Karar tarihi $=05.02 .2021$

Belge sayı numarası= Oturum: 02 Karar: 01.08 


\section{Bulgular}

Araştırmanın bu bölümünde ulaşılan bulgular tablolar şeklinde açıklamaları ile sunulmuştur:

Tablo 1.

Türkçe Öğretmenlerinin Yöntem ve Teknik Kullanma Becerileri ve Öğretmen Öz Yeterlik Algılarının Cinsiyet Değişkenine Göre Incelenmesi

\begin{tabular}{|c|c|c|c|c|c|c|c|}
\hline & Cinsiyet & $\mathrm{N}$ & $\bar{X}$ & $S S$ & $s d$ & $t$ & $p$ \\
\hline \multirow{4}{*}{ YT } & Kadın & 80 & 4.13 & .43 & \multirow{3}{*}{143} & \multirow{3}{*}{-.377} & \multirow{3}{*}{.707} \\
\hline & Erkek & 65 & & & & & \\
\hline & Toplam & 145 & 4.15 & .29 & & & \\
\hline & Cinsiyet & $\mathrm{N}$ & $\bar{X}$ & $S S$ & $s d$ & $t$ & $p$ \\
\hline \multirow{3}{*}{ OY } & Kadın & 80 & 4.24 & .47 & \multirow{3}{*}{143} & \multirow{3}{*}{-3.611} & \multirow{3}{*}{$.000^{*}$} \\
\hline & Erkek & 65 & 448 & 33 & & & \\
\hline & Toplam & 145 & & & & & \\
\hline
\end{tabular}

Not. ${ }^{*} \mathrm{p}<.001$, YT: Yöntem ve Teknik Kullanma Becerisi, OY: Öğretmen Öz Yeterliği

Türkçe öğretmenlerinin yöntem ve teknik kullanma becerileri ve öğretmen öz yeterlik algıları cinsiyet değişkenine göre bağımsız gruplar t-testi ile değerlendirilmiştir. Buna ilişkin veriler Tablo 1'de paylaşılmıştır. Tablo incelendiğinde öğretmenlerin yöntem ve teknik kullanma becerilerinin cinsiyete göre farklılık göstermediği görülmektedir $\left(t_{(143)}=-.377, p>.05\right)$. Öğretmen öz yeterlikleri ise cinsiyete göre anlamlı farklılık göstermektedir $\left(t_{(143)}=.-3.611, p<.05\right)$. Bu farklılık erkek öğretmenlerin lehinedir $(X=4.48, S S=.33)$.

Tablo 2.

Türkçe Öğretmenlerinin Yöntem ve Teknik Kullanma Becerileri ve Öğretmen Öz Yeterlik Algılarının Lisans Mezuniyeti Değişkenine Göre Incelenmesi

\begin{tabular}{|c|c|c|c|c|c|c|c|}
\hline & $\begin{array}{l}\text { Lisans } \\
\text { Mezuniyet }\end{array}$ & $\mathrm{N}$ & $\bar{X}$ & $S S$ & $s d$ & $t$ & $p$ \\
\hline \multirow{4}{*}{ YT } & Türkçe & 134 & 4.13 & .37 & \multirow{3}{*}{143} & \multirow{3}{*}{-1.115} & \multirow{3}{*}{.267} \\
\hline & Diğer Lisans & 11 & 126 & 17 & & & \\
\hline & Toplam & 145 & 4.26 & .47 & & & \\
\hline & $\begin{array}{l}\text { Lisans } \\
\text { Mezuniyet }\end{array}$ & $\mathrm{N}$ & $\bar{X}$ & $S S$ & $s d$ & $t$ & $p$ \\
\hline \multirow[b]{2}{*}{ OY } & Türkçe & 134 & 4.34 & .42 & \multirow[b]{2}{*}{143} & \multirow[b]{2}{*}{-.678} & \multirow[b]{2}{*}{.499} \\
\hline & Diğer Lisans & 11 & 4.43 & .56 & & & \\
\hline
\end{tabular}

Türkçe öğretmenlerinin yöntem ve teknik kullanma becerileri ve öğretmen öz yeterlik algıları lisans mezuniyeti değişkenine göre bağımsız gruplar t-testi ile analiz edilmiş ve bulgular Tablo 2'de sunulmuştur. Tablo 2 incelendiğinde öğretmenlerin yöntem ve teknik kullanma becerilerinin lisans mezuniyetine göre farklılık göstermediği görülmektedir $\left(t_{(143)}=-1.115, p>.05\right)$. Ayrıca öğretmen öz yeterlikleri de eğitim düzeyine göre anlamlı farklılık göstermemektedir $\left(t_{(143)}=-.678, p>.05\right)$.

Tablo 3.

Türkçe Öğretmenlerinin Yöntem ve Teknik Kullanma Becerileri ve Öğretmen Öz Yeterlik Algılarının Eğitim Düzeyi Değişsenine Göre Incelenmesi

\begin{tabular}{llcccccc}
\hline & Eğitim Düzeyi & $\mathrm{N}$ & $\bar{X}$ & $S S$ & $s d$ & $t$ & $p$ \\
\hline \multirow{4}{*}{ YT } & Lisans & 113 & 4.16 & .39 & & & \\
& Lisansüstü & 32 & 4.06 & .30 & 143 & 1.376 & .171 \\
& Toplam & 145 & & & & & \\
\hline
\end{tabular}


Türkçe Öğretmenlerinin Öğretim Yöntem ve Tekniklerini Kullanma Becerileri ile Öğretmen Öz Yeterlikleri Arasındaki Ilişki

\begin{tabular}{llcccccc}
\hline & Eğitim Düzeyi & $\mathrm{N}$ & $\bar{X}$ & $S S$ & $s d$ & $t$ & $p$ \\
\hline \multirow{3}{*}{ OY } & Lisans & 113 & 4.33 & .45 & & & \\
& Lisansüstü & 32 & & & & \\
& Toplam & 145 & 4.39 & .37 & & -.695 & .488 \\
& & & & & & & \\
\hline
\end{tabular}

Türkçe öğretmenlerinin yöntem ve teknik kullanma becerileri ve öğretmen öz yeterlik algıları eğitim düzeyi değişkenine göre Tablo 3'te sunulan bağımsız gruplar t testi ile incelenmiştir. Tablodaki veriler değerlendirildiğinde öğretmenlerin yöntem ve teknik kullanma becerilerinin eğitim düzeyine göre farklılık göstermediği anlaşılmaktadır $\left(t_{(143)}=1.376, p>.05\right)$. Bununla birlikte öğretmen öz yeterlikleri de eğitim düzeyine göre anlamlı farklılık göstermemektedir $\left(t_{(143)}=-.695, p>.05\right)$.

Tablo 4.

Türkçe Öğretmenlerinin Yöntem ve Teknik Kullanma Becerileri ve Öğretmen Öz Yeterlik Algılarının Yaş Değişkenine Göre incelenmesi

\begin{tabular}{|c|c|c|c|c|c|}
\hline YT & $\begin{array}{l}\text { Kareler } \\
\text { Toplamı }\end{array}$ & $s d$ & $\begin{array}{l}\text { Kareler } \\
\text { Ortalaması }\end{array}$ & $F$ & $p$ \\
\hline Gruplararası & .505 & 2 & .253 & \multirow{3}{*}{1.784} & \multirow{3}{*}{.172} \\
\hline Gruplariçi & 20.114 & 142 & \multirow{2}{*}{.142} & & \\
\hline Toplam & 20.619 & 144 & & & \\
\hline OY & $\begin{array}{l}\text { Kareler } \\
\text { Toplamı }\end{array}$ & $s d$ & $\begin{array}{l}\text { Kareler } \\
\text { Ortalaması }\end{array}$ & $F$ & $p$ \\
\hline Gruplararası & .978 & 2 & .489 & \multirow{3}{*}{2.640} & \multirow{3}{*}{.075} \\
\hline Gruplariçi & 26.311 & 142 & \multirow{2}{*}{.185} & & \\
\hline Toplam & 27.290 & 144 & & & \\
\hline
\end{tabular}

Türkçe öğretmenlerinin yöntem ve teknik kullanma becerilerinin ve öğretmen öz yeterlik algılarının yaş değişkenine göre incelenmesi için gerçekleştirilen tek yönlü varyans analizine ait değerler Tablo 4'te gösterilmiştir. Buna göre öğretmenlerin yöntem ve teknik kullanma becerilerinin yaşa göre anlamlı bir farklılık göstermediği görülmektedir $\left(F_{(2,142)}=1.784, p>.05\right)$. Başka bir bulguya göre öğretmen öz yeterliğinin de yaşa göre anlamlı bir farklılık göstermediği ortaya çıkmaktadır $\left(F_{(2,142)}=\right.$ $2.640, p>.05)$.

Tablo 5.

Türkçe Öğretmenlerinin Yöntem ve Teknik Kullanma Becerileri ve Öğretmen Öz Yeterlik Algılarının Meslek Yılı Değişkenine Göre Incelenmesi

\begin{tabular}{|c|c|c|c|c|c|}
\hline YT & $\begin{array}{l}\text { Kareler } \\
\text { Toplamı }\end{array}$ & $s d$ & $\begin{array}{l}\text { Kareler } \\
\text { Ortalaması }\end{array}$ & $F$ & $p$ \\
\hline Gruplararası & .287 & 2 & .144 & \multirow{3}{*}{1.003} & \multirow{3}{*}{.369} \\
\hline Gruplariçi & 20.332 & 142 & \multirow{2}{*}{.143} & & \\
\hline Toplam & 20.619 & 144 & & & \\
\hline OY & $\begin{array}{l}\text { Kareler } \\
\text { Toplamı }\end{array}$ & $s d$ & $\begin{array}{l}\text { Kareler } \\
\text { Ortalaması }\end{array}$ & $F$ & $p$ \\
\hline Gruplararası & .841 & 2 & .421 & \multirow{3}{*}{2.258} & \multirow{3}{*}{.108} \\
\hline Gruplariçi & 26.449 & 142 & \multirow{2}{*}{.186} & & \\
\hline Toplam & 27.290 & 144 & & & \\
\hline
\end{tabular}

Türkçe öğretmenlerinin yöntem ve teknik kullanma becerileri ve öğretmen öz yeterlik algıları mesleki kıdem değişkenine göre ele alınmıştır. Bu doğrultuda yararlanılan tek yönlü varyans analizine ilişkin veriler Tablo 5'te sunulmuştur. Bu bulgulardan hareketle öğretmenlerin yöntem ve teknik kullanma becerilerinin mesleki tecrübeye göre anlamlı bir farklılık göstermediği ifade edilebilir 
$\left(F_{(2,142)}=1.003, p>.05\right)$. Ayrıca öğretmen öz yeterliğinin mesleki kıdeme göre anlamlı bir farklılık göstermediği de anlaşılmaktadır $\left(F_{(2,142)}=2.258, p>.05\right)$.

Tablo 6.

Türkçe Öğretmenlerinin Yöntem ve Teknik Kullanma Becerileri ve Öğretmen Öz Yeterlik Algıları Arasındaki Ilişskinin Incelenmesi

\begin{tabular}{lllllllllll}
\hline Değişkenler & 1 & 2 & 3 & 4 & 5 & 6 & 7 & 8 & 9 & 10 \\
\hline YT (1) & 1 & & & & & & & & & \\
YT1 (2) & $.762^{*}$ & 1 & & & & & & & & \\
YT2 (3) & $.773^{*}$ & $.363^{*}$ & 1 & & & & & & & \\
YT3 (4) & $.749^{*}$ & $.450^{*}$ & $.486^{*}$ & 1 & & & & & & \\
YT4 (5) & $.560^{*}$ & $.447^{*}$ & .047 & $.388^{*}$ & 1 & & & & & \\
OY (6) & $.591^{*}$ & $.363^{*}$ & $.368^{*}$ & $.591^{*}$ & $.476^{*}$ & 1 & & & & \\
OY1 (7) & $.500^{*}$ & $.390^{*}$ & $.240^{*}$ & $.502^{*}$ & $.431^{*}$ & $.696^{*}$ & 1 & & & \\
OY2 (8) & $.572^{*}$ & $.405^{*}$ & $.307^{*}$ & $.548^{*}$ & $.504^{*}$ & $.787^{*}$ & $.458^{*}$ & 1 & & \\
OY3 (9) & $.392^{*}$ & .147 & $.265^{*}$ & $.476^{*}$ & $.321^{*}$ & $.829^{*}$ & $.331^{*}$ & $.592^{*}$ & 1 & \\
OY4 (10) & $.484^{*}$ & $.309^{*}$ & $.356^{*}$ & $.411^{*}$ & $.335^{*}$ & $.859^{*}$ & $.631^{*}$ & $.514^{*}$ & $.560^{*}$ & 1 \\
\hline Ortalama & 4.14 & 3.70 & 4.30 & 4.37 & 3.93 & 4.35 & 4.33 & 4.51 & 4.47 & 4.06 \\
\hline SS & .37 & .66 & .43 & .44 & .73 & .43 & .49 & .45 & .57 & .61 \\
\hline
\end{tabular}

Not. ${ }^{\mathrm{p}} \mathrm{p}<.001, \mathrm{~N}=145$; SS: Standart Sapma, YT: Yöntem ve Teknik Kullanma Becerisi Ölçeği Genel, YT1: Yöntem ve Teknik Kullanma Becerisi Faktör 1, YT2: Yöntem ve Teknik Kullanma Becerisi Faktör 2, YT3: Yöntem ve Teknik Kullanma Becerisi Faktör 3, YT4: Yöntem ve Teknik Kullanma Becerisi Faktör 4, OY: Öğretmen Öz Yeterlik Ölçeği Genel, OY1: Öğretmen Öz Yeterlik Faktör 1, OY2: Öğretmen Öz Yeterlik Faktör 2, OY3: Öğretmen Öz Yeterlik Faktör 3, OY4: Öğretmen Öz Yeterlik Faktör 4.

Tablo 6 incelendiğinde, öğretmenlerin yöntem ve teknik kullanma becerileri ve öğretmen öz yeterlikleri arasında pozitif yönlü anlamlı bir ilişki $(r=.59, p<.001 ; 95 \% C I=.47, .68)$ olduğu görülmektedir. Ayrıca yöntem ve teknik kullanma becerisi ölçeğinin kendi alt faktörleri ile öğretmen öz yeterliği ölçeğinin alt faktörleri arasında anlamlı pozitif ilişkiler tespit edilmiştir. Bunlar Tablo 6'dan ayrıntılı bir şekilde incelenebilir. Buna göre öğretmenlerin yöntem ve teknik kullanma becerileri yükseldikçe, öğretmen öz yeterlik algılarının da arttığı söylenebilir.

Öğretmenlerin öğretim yöntem ve teknik kullanma becerilerinin öğretmen öz yeterliğini ne ölçüde yordadığını ortaya koymak için basit doğrusal regresyon analizinden yararlanılmıştır. Regresyon analizinden önce bazı ön kontroller yapılmış, değişkenlerin ikili ilişkileri incelenmiş ve çoklu eş doğrusallığın olmamasına dikkat edilmiştir. Oto korelasyon durumu Durbin-Watson değeri doğrultusunda sorgulanmış ve elde edilen değerin (1.87) normal sınırlar arasında olduğu tespit edilmiştir (Field, 2009). İkinci olarak bağımsız değişkenin açıklayamadığı varyans oranı olan tolerans değeri $\left(1-R^{2}\right)$ ile varyans büyütme faktörü (VIF) analiz edilmiştir. Tolerans değeri .20 değerinden daha büyük ve varyans büyütme faktörü $(V I F=1.0) 10$ değerinden daha düşük olduğu için çoklu bağıntı probleminin olmadığı anlaşılmışır (Field, 2009).

Tablo 7.

Öğretmen Öz Yeterliğinin Yordayıcısı Olarak Yöntem ve Teknik Kullanma Becerisi

\begin{tabular}{|c|c|c|c|c|c|}
\hline & B & SE & $\beta$ & $t$ & $p$ \\
\hline Sabit & 1.533 & .323 & & 4.749 & $<.001$ \\
\hline YT & .680 & .078 & .59 & 8.770 & $<.001$ \\
\hline
\end{tabular}

Not. $k=5000, R^{2}=.35, \Delta R^{2}=.34, p<.001$, YT (Bağımsız Değişken): Yöntem ve Teknik Kullanma Becerisi, Bağımlı Değişken: Öğretmen Öz Yeterlik Algısı

Öğretmen öz yeterliğinin yordayıcısı, Tablo 7'de gösterilmiştir. Gerekli ön koşulların sağlanmasının ardından gerçekleştirilen basit doğrusal regresyon analizi sonucunda, yöntem ve teknik 
Türkçe Öğretmenlerinin Öğretim Yöntem ve Tekniklerini Kullanma Becerileri ile Öğretmen Öz Yeterlikleri Arasındaki ilişki

kullanma becerisinin, öğretmen öz yeterlik toplam varyansının \%34'ünü açıkladığı belirlenmiştir $\left(F_{(1,143)}=76.905, p<.001\right)$. Yöntem ve teknik kullanma becerisinin regresyon modeline pozitif katkısının anlamlı $(\beta=.59, p<.001 ; 95 \% C I=.52, .83)$ olduğu belirlenmiştir.

\section{Tartışma ve Sonuç}

Araştırmada, Türkçe öğretmenlerinin yöntem ve teknik kullanma becerileri cinsiyete, lisans mezuniyet bölümlerine, eğitim durumlarına, yaş gruplarına, mesleki deneyim yıllarına göre anlamlı farklııı göstermemektedir. Sügü̈mlü ve Sulak (2020) tarafından yürütülen araştırmada da cinsiyete, yaşa, eğitim durumuna, lisans mezuniyet bölümüne göre Türkçe öğretmenlerinin yöntem ve teknik kullanma becerileri değişmemiştir. Bunların yanı sıra Süğümlü ve Sulak'ın (2020) çalışmasında öğretmenlerin mesleki deneyimlerine göre yöntem ve teknik kullanma becerileri farklılık göstererek meslek yılı artan grupların becerileri de daha yüksek olarak belirlenmiştir.

Türkçe öğretmenlerinin öğretmen öz yeterlik algıları cinsiyete göre erkekler lehine anlamlı farklıık göstermiştir. Bu durum alanda yapılan bazı çalışmaların sonuçları ile örtüşmezken (Ekici, 2006; Ünlü, Kaşkaya ve Kızılkaya, 2017), bazı çalışmalar da yürütülen çalışmanın sonuçlarıyla uyuşmaktadır (Demirtaş, Cömert ve Özer, 2011; Izgar ve Dilmaç, 2008; Korkuk ve Babaoğlan, 2012; Yeşilyurt, 2013). Bunun yanı sıra pek çok çalışmada öğretmen öz yeterliğinin cinsiyete göre değişmediği görülmüştür (Altıntaş, Özdemir ve Kerpiç, 2012; Aslan ve Kalkan, 2018; Azar, 2010; Baykara, 2011; Ercan-Özaydın, Çavaş ve Arslan-Cansever, 2017; Uzun, Özkılıç ve Şentürk, 2010; Üstüner, vd., 2009; Saracoğlu, Karasakaloğlu ve Gencel, 2010; Tejeda-Delgado, 2009).

Öğretmenlerin öz yeterlik algıları lisans mezuniyet bölümüne, eğitim durumuna, yaşına ve mesleki deneyim yılına göre araştırmada anlamlı farklılık göstermemiştir. Buna karşılık yapılan çeşitli araştırmalarda öğretmen öz yeterlik algılarının eğitim durumuna (Aslan ve Kalkan, 2018), mesleki deneyim yılına göre (Aslan ve Kalkan, 2018; Saracoğlu, Karasakaloğlu ve Gencel, 2010) anlamlı farklılık gösterdiği görülmektedir. Güvenç (2011) ise öğretmenlerin kıdemlerinin arttıkça öz yeterlik algısı puanlarının azaldığını belirtmektedir. Bazı araştırmalarda da burada olduğu gibi öğretmen öz yeterlik algıları lisans mezuniyet bölümüne (Saracoğlu, Karasakaloğlu ve Gencel, 2010), eğitim durumuna (Üstüner, vd., 2009), mesleki deneyim yılına (Ekici, 2006; Korkut ve Babaoğlan, 2012; Üstüner, vd., 2009) göre anlamlı farklılık göstermemiştir.

Araştırmada, öğretmenlerin yöntem ve teknik kullanma becerileri ve öğretmen öz yeterlikleri arasında pozitif yönlü anlamlı bir ilişki olduğu bulunmuştur. Ayrıca basit doğrusal regresyon analizi ile yöntem ve teknik kullanma becerisinin, öğretmen öz yeterlik toplam varyansının \%34'ünü açıkladığı belirlenmiştir. Literatür tarandığında doğrudan araştırma konusu ile ilgili yapılmış çalışmaya rastlanmamıştır. Zee ve Koomen (2016) öğretmen öz yeterliliği ile öğrencilerin akademik uyumu, öğretmen davranış kalıpları ve sınıf kalitesiyle ilgili uygulamaları, öğretmenin kişisel başarısı, iş tatmini ve bağlılık dâhil öğretmenlerin psikolojik refahının altında yatan faktörler ile olumlu bağlantılar olduğunu belirtmektedir. Kim ve Seo (2018) yapılan 16 çalışma ve 4130 öğretmeni içeren meta analiz araştırmasında öğretmen yeterliği ile öğrencilerin akademik başarısı arasındaki ortalama ilişkinin anlamlı olduğu sonucuna ulaşmışlardır. Buradan görülmektedir ki öğretmen öz yeterliği eğitimde oldukça etkili bir değişkendir. Bu sebeple yeterliğin yükselmesi eğitim kalitesini de geliştirecek bir durum olarak ortaya çıkmaktadır. Araştırma sonucunda öğretmenlerin yöntem ve teknik kullanma becerileri öğretmen öz yeterliklerinin anlamlı bir yordayıcısı olmuştur. Bu sonuç yöntem ve teknik kullanma becerisinin öğretmen öz yeterliğini etkilediği şeklinde yorumlanabilir. Böylelikle öğretmenlerin yöntem ve teknik kullanma becerilerinin geliştirilmesi ile öğretmen öz yeterliği de olumlu yönde etkilenebilir.

Dirican (2014) tarafından yapılan çalışmada öğretmenlerin öğrenci merkezli öğretim sürecine dair görüşleri ile öz yeterlik algıları arasında olumlu bir ilişki tespit edilmiştir. 2005 yılından itibaren Türkiye'de yapılandırmacı yaklaşımın hâkim olduğu öğretim programları bulunmaktadır. Öğretim programlarında önerilen yöntem ve tekniklerin de öğrenci merkezli uygulanacağı düşünülmektedir. Bu bakımdan Dirican'ın çalışmasında elde edilen öğrenci merkezli eğitime öğretmenlerin bu tarzdaki eğitimi uygularken kullandıkları yöntem ve teknikler de dâhil olabilir. Dolayısıyla günümüzdeki öğretim 
programına uygun yöntem ve tekniklerin kullanma becerileri ile öğretmenlerin öz yeterlikleri arasında ilişki kurulabilir.

Yapılan araştırmadan ve diğer araştırmalardan da anlaşıldığı gibi öğretmenlerin öz yeterliklerinin, onların uyguladığı eğitim-öğretim stilleri, öğretim yöntem ve tekniklerini uygulamaları ile anlamlı ilişkisi vardır. Literatür bölümünde ve tartışma bölümünde yer alan diğer çalışmalarda da öğretmen öz yeterliğinin öğrenci başarısıyla ve mesleki tutumla ilişkili olduğu görülmektedir. Yani öğretmenlerin öğretim yöntem ve tekniklerini kullanma becerilerinin gelişmesinin birden çok faydasının olabileceği düşünülmektedir.

Araştırmadan elde edilen sonuçlara göre şu öneriler sunulabilir:

1. Öğretmenlerin, öğretim yöntem ve tekniklerini kullanma becerileri ile öğretmen öz yeterlikleri arasında anlamlı pozitif ilişki olması sebebiyle, öğretmenlik lisans programında yöntem ve teknikler ile ilgili derslere daha fazla önem verilebilir.

2. Bu araştırmada yapılan inceleme ve analizler farklı̈ örneklemlerle tekrar edilerek bu konu ile ilgili bulgular temellendirilebilir.

3. Öğretmenlerin, öğretim yöntem ve tekniklerini kullanma becerileri ile öğretmen öz yeterlikleri nitel yöntemler kullanılarak incelenebilir.

\section{Araştırma ve Yayın Etiği}

Bu çalışmada "Yükseköğretim Kurumları Bilimsel Araştırma ve Yayın Etiği Yönergesi" kapsamında uyulması belirtilen tüm kurallara uyulmuştur. Yönergenin ikinci bölümü olan "Bilimsel Araştırma ve Yayın Etiğine Aykırı Eylemler" başlığı altında belirtilen eylemlerden hiçbiri gerçekleştirilmemiştir.

\section{Etik Kurul İni}

Kurul adı = Tokat Gaziosmanpaşa Üniversitesi Sosyal ve Beşerî Bilimler Araştırmaları Etik Kurulu Karar tarihi $=05.02 .2021$

Belge sayı numarası= Oturum: 02 Karar: 01.08

\section{Yazarların Katkı Oranı}

Çalışmaya birinci yazar \%50, ikinci yazar \%50 oranında katkı sağlamıştır.

\section{Çıkar Çatışması}

Bu araştırmada çıkar çatışması teşkil edebilecek herhangi bir durum ya da ilişki yoktur.

\section{Destek ve Teşekkür}

Çalışmaya katılım sağlayan Türkçe öğretmenlerine teşekkürlerimizi sunarız.

\section{Kaynaklar}

Akgün, F. (2013). Öğretmen adaylarının web pedagojik içerik bilgileri ve öğretmen öz-yeterlik algıları ile ilişkisi. Trakya Üniversitesi Eğitim Fakültesi Dergisi, 3(1), 48-58.

Allinder, R. M. (1994). The relationship between efficacy and the instructional practices of special education teachers and consultants. Teacher education and special education, 17(2), 86-95.

Altıntaş, E., Özdemir, A. Ş. ve Kerpiç, A. (2012). Öğretmen adaylarının matematik okuryazarlığı özyeterlik algılarının bölümlere göre karşılaştırılması. Trakya Üniversitesi Eğitim Fakültesi Dergisi, 2(2), 26-34.

Arastaman, G. (2013). Eğitim ve fen edebiyat fakültesi öğrencilerinin öz-yeterlik inançları ve öğretmenlik mesleğine karşı tutumlarının incelenmesi. Journal of Kirsehir Education Faculty, 14(2), 205-217.

Arıcl, A. F. (2006). Türkçe öğretiminde kullanılan strateji-yöntem ve teknikler. Atatürk Üniversitesi Sosyal Bilimler Enstitüsü Dergisi, 7(1), 299-307. 
Türkçe Öğretmenlerinin Öğretim Yöntem ve Tekniklerini Kullanma Becerileri ile Öğretmen Öz Yeterlikleri Arasındaki ilişki

Ashton, P. T. (1985). Motivation and teacher's sense of efficacy. In C. Ames ve R. Ames (Eds.), Research on motivation in education: Vol. 2. The classroom meliu (s. 141-174). Orlando, FL: Academic Press.

Ashton, P. T., \& Webb, R. (1986). Making a difference: Teachers' sense of efficacy and student achievement. New York: Longman.

Aslan, M. ve Kalkan, H. (2018). Öğretmenlerin özyeterlik algılarının analizi. Bingöl Üniversitesi Sosyal Bilimler Enstitüsü Dergisi, 8(16), 477-494.

Azar, A. (2010). Ortaöğretim fen bilimleri ve matematik öğretmeni adaylarının öz yeterlilik inançları. ZKÜ Sosyal Bilimler Dergisi, 6(12), 235-252.

Bakaç, E. ve Raşit, Ö. (2017). Pedagojik formasyon öğrencilerinin öğretmenlik mesleğine yönelik özyeterlik inançları ile tutumları arasındaki ilişki. Kastamonu eğitim dergisi, 25(4), 1389-1404.

Bandura, A. (1977). Self efficacy: Toward a unifying theory of behavioral change. Psychological Review, 84(2), 191-215.

Bandura, A. (1997). Exercise of personal and collective efficacy in changing societies. In A. Bandura (Ed.), Self efficacy in changing societies (s. 1-45). Cambridge, United Kingdom: Cambridge University Press.

Baykara, K. (2011). Öğretmen adaylarının bilişötesi öğrenme stratejileri ile öğretmen yeterlik algıları üzerine bir çalışma. Hacettepe Üniversitesi Eğitim Fakültesi Dergisi, 40, 80-92.

Bayrakdar, U., Vural-Batık, M. ve Barut, Y. (2016). Özel eğitim öğretmen adaylarının öğretmen özyeterlik düzeyleri ve öğretmenlik mesleğine yönelik tutumları. Journal of Kirsehir Education Faculty, 17(2), 133-149.

Berkant, H. G. ve Ekici, G. (2007). Sınıf öğretmeni adaylarının fen öğretiminde öğretmen öz yeterlik inanç düzeyleri ile zeka türleri arasındaki ilişkinin değerlendirilmesi. Çukurova Üniversitesi Sosyal Bilimler Enstitüsü Dergisi, 16(1), 113-132.

Christensen, L. B., Johnson, R. B., \& Turner, L. A. (2015). Research methods, design, and analysis (12th ed.). New Jersey: Pearson.

Creswell, J. W. (2012). Educational research: Planning, conducting, and evaluating quantitative and qualitative research (4th ed.). New Jersey: Pearson.

Çapa-Aydın, Y., Uzuntiryaki-Kondakçı, E., Temli, Y. ve Tarkın, A. (2013). Adaptation of sources of selfefficacy inventory into Turkish. Ilköğretim Online, 12(3), 749-758.

Çolak, I., Yorulmaz, Y. İ. ve Altınkurt, Y. (2017). Öğretmen özyeterlik inancı ölçeği geçerlik ve güvenirlik çalışması. Muğla Sıtkı Koçman Üniversitesi Eğitim Fakültesi Dergisi, 4(1), 20-32.

Dal, S. ve Tatar, N. (2017). Temel kavramlar. S. Dal ve M. Köse (Edt.), Öğretim ilke ve yöntemleri içinde (ss. 1-45). Ankara: Anı Yayıncılık.

Dellinger, A. B. (2001). A study of the measurement and sources of teachers' self and collective efficacy beliefs in professional learning environments (Unpublished doctoral dissertation). Louisiana State University, Baton Rouge, Louisiana.

Dellinger, A. B., Bobbett, J. J., Olivier, D. F., \& Ellett, C. D. (2008). Measuring teachers' self-efficacy beliefs: Development and use of the TEBS-Self. Teaching and teacher education, 24(3), 751766.

Demirtaş, H., Cömert, M. ve Özer, N. (2011). Öğretmen adaylarının özyeterlik inançları ve öğretmenlik mesleğine ilişkin tutumları. Eğitim ve Bilim, 36(159), 96-111.

Dirican, E. E. (2014). Matematik öğretmenlerinin öz-yeterliklerini etkileyen faktörlerin incelenmesi (Yayımlanmamış yüksek lisans tezi). Balıkesir Üniversitesi, Fen Bilimleri Enstitüsü, Balıkesir.

Ekici, G. (2006). Meslek lisesi öğretmenlerinin öğretmen öz-yeterlik inançları üzerine bir araştırma. Eurasian Journal of Educational Research (EJER), 24, 87-96.

Ekici, G. (2008). Sınıf yönetimi dersinin öğretmen adaylarının öğretmen öz-yeterlik algı düzeyine etkisi. Hacettepe Üniversitesi Eğitim Fakültesi Dergisi, 35, 98-110.

Ekinci, N. (2015). Öğretmen adaylarının öğrenme yaklaşımları ve öğretmen özyeterlik inançları arasındaki ilişki. Hacettepe Üniversitesi Eğitim Fakültesi Dergisi, 30(1), 62-76.

Ercan-Özaydın, T., Çavaş, P. ve Arslan-Cansever, B. (2017). Sınıf öğretmeni adaylarının özyeterlik inançlarının değerlendirilmesi. Ege Eğitim Dergisi, 18(1), 1-30. 
Federici, R. A., \& Skaalvik, E. M. (2012). Teacher and principal self-efficacy: Relations with autonomy and emotional exhaustion. In S. L. Britner (Ed.), Perspectives on cognitive psychology. Selfefficacy in school and community settings (s. 125-150). New York: Nova Science Publishers.

Field, A. (2009). Discovering statistics using SPSS (3rd ed.). CA: Sage.

Fraenkel, J. R., Wallen, N. E., \& Hyun, H. H. (2012). How to design and evaluate research in education (8th ed.). Boston: McGraw-Hill.

Gay, L. R., Mills, G. E., \& Airasian, P. W. (2011). Educational research: Competencies for analysis and application (10th ed.). Boston: Pearson.

George, D., \& Mallery, M. (2003). Using SPSS for Windows step by step: a simple guide and reference. Boston: Allyn and Bacon.

Guskey, T. R., \& Passaro, P. D. (1994). Teacher efficacy: A study of construct dimensions. American Educational Research Journal, 31, 627-643.

Güvenç, H. (2011). Sınıf öğretmenlerinin özerklik destekleri ve mesleki özyeterlik algıları. Kuram ve Uygulamada Eğitim Yönetimi Dergisi, 17(1), 99-116.

Infurna, C., Riter, D., \& Schultz, S. (2018). Factors that determine preschool teacher self-efficacy in an urban school district. International Electronic Journal of Elementary Education, 11(1), 1-7.

Izgar, H. ve Dilmaç, B. (2008). Yönetici adayı öğretmenlerin özyeterlik algıları ve epistemolojik inançlarının incelenmesi. Selçuk Üniversitesi Sosyal Bilimler Enstitüsü Dergisi, 20, 437-446.

Jöreskog, K. G., \& Sörbom, D. (1993). Lisrel 8: Structural equation modeling with simpliscomm and language. Lincolnwood: Scientific Software International.

Kim, K. R., \& Seo, E. H. (2018). The relationship between teacher efficacy and students' academic achievement: A meta-analysis. Social Behavior and Personality: an international journal, 46(4), 529-540.

Kline, R. B. (2011). Principles and practice of structural equation modeling (3rd ed.). New York, NY: Guilford Press.

Korkut, K. ve Babaoğlan, E. (2012). Sınıf öğretmenlerinin öz yeterlik inançları. Uluslararası Yönetim iktisat ve Işletme Dergisi, 8(16), 269-281.

Kutluca, A. Y. ve Aydın, A. (2016). Fen bilgisi öğretmen adaylarının öz-yeterlik inançlarının çeşitli değişkenler açısından incelenmesi: Oluşturmacı öğretimin etkisi. Abant izzet Baysal Üniversitesi Eğitim Fakültesi Dergisi, 16(1), 217-236. DOI: 10.17240/aibuefd.2016.16.15000182919

MEB. (2019). Türkçe dersi öğretim programı. Ankara: Talim ve Terbiye Kurulu Başkanlığı.

Moore, W. ve Esselman, M. (1992). Teacher efficacy, power, school climate and achievement: A desegregating district's experience. Paper presented at the annual meeting of the American Educational Research Association, San Francisco.

Nakip, C. ve Özcan, G. (2016). Öğretmen adaylarının öğretmenlik mesleğine yönelik öz-yeterlik inançları ile öğretmenlik mesleğine yönelik tutumları arasındaki ilişki. Mersin University Journal of the Faculty of Education, 12(3), 783-795.

Pajares, F. (1996). Self-efficacy beliefs in academic settings. Review of Educational Research, 66(4), 543-578.

Recepoğlu, E. (2013). Öğretmen adaylarının yaşam doyumları ile öğretmenlik mesleğine ilişkin tutumları arasındaki ilişkinin incelenmesi. Hacettepe Üniversitesi Eğitim Fakültesi Dergisi, Özel(1), 311-326.

Robson, C., \& McCartan, K. (2016). Real world research. West Sussex: John Wiley \& Sons.

Skaalvik, E. M., \& Skaalvik, S. (2007). Dimensions of teacher self-efficacy and relations with strain factors, perceived collective teacher efficacy, and teacher burnout. Journal of Educational Psychology, 99, 611-625.

Soodak, L. C., \& Podell, D. M. (1993). Teacher efficacy and student problem as factors in special education referral. The Journal of Special Education, 27(1), 66-81.

Süğümlü, Ü. ve Sulak, S. E. (2020). Türkçe öğretim yöntem ve tekniklerini kullanma becerisi ölçeğinin geliştirilmesi: Geçerlik ve güvenirlik çalışması. Dil Dergisi, 171, 147-171. 
Türkçe Öğretmenlerinin Öğretim Yöntem ve Tekniklerini Kullanma Becerileri ile Öğretmen Öz Yeterlikleri Arasındaki ilişki

Tabachnick, B. G., \& Fidell, L. S. (2007). Using multivariate statistics (5th ed.). New York: Allyn and Bacon.

Tejeda-Delgado, M. D. C. (2009). Teacher efficacy, tolerance, gender, and years of experience and special education referrals. International Journal of Special Education, 24(1), 112-119.

Tschannen-Moran, M., \& Hoy, A. W. (2001). Teacher efficacy: Capturing an elusive construct. Teaching and teacher education, 17(7), 783-805.

Tschannen-Moran, M., Hoy, A. W., \& Hoy, W. K. (1998). Teacher efficacy: Its meaning and measure. Review of Educational Research, 68(2) 202-248. Retrieved from http://www.jstor.org/stable/1170754

Uzun, A., Özkılıç, R. ve Şentürk, A. (2010). A case study: Analysis of teacher self-efficacy of teacher candidates. Procedia-Social and Behavioral Sciences, 2(2), 5018-5021.

Ünlü, ì., Kaşkaya, A. ve Kızılkaya, M. F. (2017). Sosyal bilgiler öğretmen adaylarının öz-yeterlik inançlarının çeşitli değişkenler açısından incelenmesi. Journal of Kirsehir Education Faculty, 18(2), 651-668.

Üstüner, M., Demirtaş, H., Cömert, M. ve Özer, N. (2009). Ortaöğretim öğretmenlerinin öz-yeterlik algıları secondary school teachers' self-efficacy beliefs. Mehmet Akif Ersoy Üniversitesi Eğitim Fakültesi Dergisi, 9(17), 1-16.

Woolfolk, A. E., \& Hoy, W. K. (1990). Prospective teachers' sense of efficacy and beliefs about control. Journal of Educational Psychology, 82, 81-91.

Yaman, S. ve Yalçın, N. (2005). Fen eğitiminde probleme dayalı öğrenme yaklaşımının problem çözme ve öz-yeterlik inanç düzeylerinin gelişimine etkisi. Hacettepe Üniversitesi Eğitim Fakültesi Dergisi, 29, 229-236.

Yeşilyurt, E. (2013). Öğretmen adaylarının öğretmen öz-yeterlik algıları. Electronic Journal of Social Sciences, 12(45), 88-104.

Yıldız, H. (2012). Üst biliş stratejilerinin öğretmen adaylarının üst bilişsel farkındalıklarına ve öz yeterliklerine etkisi (Yayımlanmamış doktora tezi). İnönü Üniversitesi Eğitim Bilimleri Enstitüsü, Malatya.

Zee, M., \& Koomen, H. M. (2016). Teacher self-efficacy and its effects on classroom processes, student academic adjustment, and teacher well-being: A synthesis of 40 years of research. Review of Educational Research, 86(4), 981-1015.

\section{Extended Abstract}

\section{Introduction}

In social cognitive theory, Bandura discussed the concept of self-efficacy, which expresses the belief in one's ability to organize and execute the necessary action plans to manage possible situations (Bandura, 1997). Efficacy belief affects how people think, feel, motivate themselves and behave (Bandura, 1997). The concept of self-efficacy covers a broad set of contents because self-efficacy deals with a person's stance on all the occurrences they may encounter. In other words, this concept is not specifically limited to the teaching profession, thus enabled the creation of a field of study which examines self-efficacy particularly in the teaching profession. In the studies carried out on teacher efficacy in the 1970s, Bandura's theory was not mentioned (Dellinger, Bobbett, Oliver, \& Ellett, 2008); after the 1980s, studies on teacher self-efficacy gained momentum (Çapa-Aydin, Uzuntiryaki-Kondakçı, Temli \& Tarkın, 2013). Thus, it can be said that the interest in the subject of teacher self-efficacy started with the theoretical-based studies, and this interest has increased to the present day.

Ashton (1985) defined teacher competence as teachers' belief in their ability to have a positive effect on students' learning. Tschannen-Moran, Hoy, and Hoy (1998) defined teacher competence as teachers' belief in their ability to organize and carry out the actions required to successfully perform a particular teaching task in a given context. Dellinger (2001) suggests the theory that teacher efficacy and teacher self-efficacy beliefs are structured differently and therefore, teacher competence and teacher self-efficacy need to be conceptualized and measured differently. Teacher self-efficacy is defined as the individual beliefs of teachers in their ability to fulfil certain teaching tasks up to a certain 
standard in a given situation (Dellinger, Bobbett, Oliver \& Ellett, 2008). Thus, this concept can be evaluated as a situation that affects the teaching activities and the quality of the teaching.

Teachers' method-technique usage skills may affect their self-efficacy perception. In the formal education process, lessons are taught according to specific methods and techniques. If the teacher specializes in these, it may affect their belief that they will fulfil the requirements of their profession better.

The use of method-technique in the field of education is an important factor in the quality of education. Teachers' perceptions of professional self-efficacy are also very pertinent to education as can be deduced from the findings of the studies carried out. Determining the relationship between these two variables has been deemed necessary in order to present a more immersive perspective to the current literature.

The main purpose of the study is to determine the relationship between Turkish teachers' method and technique usage skills and their self-efficacy beliefs.

\section{Method}

This study was carried out with relational research, one of the quantitative research designs which excludes manipulation of an independent variable (Christensen, Johnson \& Turner, 2015). Creswell (2012) defines relational studies as procedures in quantitative research in which researchers measure the degree of relationship between two or more variables using correlational statistical analysis.

As part of the research, 145 Turkish teachers working in various cities of Turkey participated in the study.

Using Turkish Teaching Methods and Techniques Skill Scale: The scale prepared in 5-point likert type; it consists of 4 factors and 26 items: "Collaborative", "Invention", "Presentation" and "Teaching through Research and Analysis". The Cronbach Alpha reliability coefficient of this scale was determined as .80. DFA fit statistics were calculated as GFI $=.92$, RMSEA $=.061, \mathrm{NFI}=.92, \mathrm{CFI}=.93, \chi 2 / \mathrm{df}=1.92$, AGFI = .91 (Süğümlü \& Sulak, 2020). In this study, the reliability analysis of the scale was calculated. Accordingly, the Cronbach Alpha value of the scale was determined as .85 $(95 \% \mathrm{Cl}=.82, .89)(\mathrm{n}=145)$.

Teacher Self-Efficacy Scale: The scale has 27 items, four-factor and 5-point likert type, which are Academic Self-Efficacy, Professional Self-Efficacy, Social Self-Efficacy and Intellectual Self-Efficacy. The accuracy of the scale was tested with DFA. When the findings obtained in this way were analyzed, it was observed that the ratio of $\chi 2 / \mathrm{df}$ was 2.12. The data for other goodness of fit indices are as follows: $\mathrm{NNFI}=.97, \mathrm{AGFI}=.82, \mathrm{GFI}=.85, \mathrm{RMSEA}=.06, \mathrm{RMR}=.03, \mathrm{CFI}=.97, \mathrm{SRMR}=.06, \mathrm{NFI}=.95$. The Cronbach Alpha value of the scale was determined as .93 (Çolak, Yorulmaz \& Altınkurt, 2017). In this study, the reliability analysis of the scale was calculated. Accordingly, the Cronbach Alpha value was determined as $.93(95 \% \mathrm{Cl}=.91, .94)(\mathrm{n}=145)$.

Analyses were performed by using SPSS 24 and JASP computer programs. Statistical techniques were chosen according to the normality values of the distributions of the data in the analyses to be made within these programs. The data were analyzed using one-way ANOVA, Pearson productmoment correlation coefficient, independent groups t-test, simple linear regression analysis.

\section{Result and Discussion}

In the study, Turkish teachers' method and technique usage skills did not differ significantly according to gender, bachelor graduation departments, educational status, age groups, and years of professional experience. In the study conducted by Sügüumlü and Sulak (2020), Turkish teachers' method and technique usage skills did not vary according to gender, age, education level and undergraduate graduation department. However, method and technique usage skills differed according to the teachers' professional experiences: The skills of the groups with longer professional experience were determined to be higher.

When considering gender as a factor, Turkish teachers' self-efficacy perceptions differed in favor of males. While this situation is in contrast to some studies in the field (Ekici, 2006; Ünlü, Kaşkaya \& Kızılkaya, 2017), some studies also agree with this finding (Demirtaş, Cömert \& Özer, 2011; Izgar \& 
Türkçe Öğretmenlerinin Öğretim Yöntem ve Tekniklerini Kullanma Becerileri ile Öğretmen Öz Yeterlikleri Arasındaki ilişki

Dilmaç, 2008; Korkuk \& Babaoğlan, 2012; Yeşilyurt, 2013). Furthermore, more studies conclude that gender does not have a significant effect on teacher self-efficacy (Altıntaş, Özdemir \& Kerpiç, 2012; Aslan \& Kalkan, 2018; Azar, 2010; Baykara, 2011; Ercan-Özaydın, Çavaş \& Arslan-Cansever, 2017; Uzun, Özkılıç \& Şentürk, 2010; Saracoğlu, Karasakaloğlu \& Gencel, 2010; Tejeda-Delgado, 2009; Üstüner, et al., 2009).

Self-efficacy perceptions of teachers did not differ significantly in the study according to their bachelor graduation department, educational status, age, and professional experience years. On the other hand, in various studies, it is seen that teachers' self-efficacy perceptions differ significantly according to education status (Aslan \& Kalkan, 2018) and professional experience (Aslan \& Kalkan, 2018; Saracoğlu, Karasakaloğlu \& Gencel, 2010). Güvenç (2011) states that as the seniority of teachers increases, their self-efficacy perception scores decrease.

In the study, it was found that there is a positive and significant relationship between teachers' method and technique usage skills and teacher self-efficacy. In addition, the simple linear regression analysis - determined that the skill of using methods and techniques explained $34 \%$ of the total variance of teacher self-efficacy. Zee and Koomen (2016) state that there are positive links with teacher self-efficacy and factors underlying teachers' psychological well-being including students' academic compliance, teacher behaviour patterns and classroom quality practices, teachers' personal success, teachers' job satisfaction and commitment. Kim and Seo (2018) concluded in a meta-analysis study involving 16 studies and 4130 teachers that the average relationship between teacher efficacy and students' academic achievement is significant. From this study, it can be concluded that teacher selfefficacy is a very influential variable in education. For this reason, increasing the competence of teachers is presumed to improve the quality of education. As evidenced by the positive and significant relationship between teachers' method and technique use skills and teacher self-efficacy, the skill of using method and technique may affect teacher self-efficacy. 